Geophysical Research Abstracts,

Vol. 11, EGU2009-9041, 2009

EGU General Assembly 2009

(C) Author(s) 2009

\title{
The long range transport of birch (Betula) pollen from Poland and Germany causes significant pre-season concentrations in Denmark
}

\author{
C. Ambelas Skjoth (1), J. Sommer (2), A. Stach (3), M. Smith (4), J. Brandt (1), J. H. Christensen (1), L. M. \\ Frohn (1), C. Geels (1), K. M. Hansen (1), and G. B. Hedegaard (1) \\ (1) National Environmental Research Institute, Dept. of Atmospheric Environment, Roskilde, Denmark (cas@dmu.dk, \\ 0045-4630-1214), (2) Asthma-Allergy Association, Denmark, (3) Laboratory of Aeropalynology, Adam Mickiewicz \\ University, Poznań, Poland, (4) National Pollen and Aerobiology Research Unit, University of Worcester, Worcester, UK
}

In Denmark, where birch pollen is considered to be among the most important allergenic pollen, about one million people suffer from seasonal allergic rhinitis. In Denmark, the official reported pollen forecast is based on the daily weather forecast, the pollen calendar and local 24-h measurements. Birch pollen has the potential for long-range transport but the present Danish pollen forecast does not account for birch pollen being transported into the country from distant sources.. Long-range transport episodes are intermittent and often out of the main pollen season, where individuals in general will be medically unprotected. Here we use an integrated approach to investigate whether or not Denmark receives significant quantities of birch pollen from Poland and Germany before local trees start to flower.

In 2006 we used a combination of phenological observations and pollen measurements in Poland (Poznań) and Denmark (Copenhagen). Seasonal and diurnal variations in birch pollen measurement from Copenhagen (2000-2006) were examined with the aim of identifying pre-seasonal episodes originating from long-range transport. The $2.5 \%$ accumulation method was used for identifying start of season. If daily pollen counts exceeded 30 grains/m3 either before the local flowering season began or on the actual start day, the episode was chosen for investigation with back trajectory analysis. A birch forest inventory for Northern Europe was produced and implemented in DEHM-Pollen along with a simple unified pollen release model SUPREME to investigate the 2006 campaign in detail.

In 2006, full flowering took place in Poznan between 20th and 28th of April and daily concentrations varied between 739 and 2169 grains $/ \mathrm{m} 3$. In Copenhagen phenological observations showed that local flowering was initiated the 2nd of May. In Copenhagen several episodes with pollen concentrations at 108, 244 and 41 grains $/ \mathrm{m} 3$ were recorded the 23rd, 26th and 27th of April, respectively. Back-trajectory analysis showed that for those tree dates the origin of the air masses was Poland including the Poznan region.

11 possible pre-seasonal long-range transport episodes in 2000-2006 were identified during analyses of the measured pollen data. All possible long-range transport episodes were investigated with back trajectories. In all investigated episodes, the air masses Copenhagen originated directly from either Germany or Poland.

The model results from DEHM pollen for 2006 show several episodes in Copenhagen with high pollen concentration for the 23rd - 24th and 26th - 27th of April, respectively. These pre-seasonal peaks in 2006 were modelled well with respect to timing and magnitude. During this period the SUPREME model only predicts birch pollen emission south of Denmark.

Long-range transport episodes of birch pollen from Poland and Germany has happened almost every year since 2000 and it is therefore likely that this is a general pattern. It is shown that DEHM-Pollen for the year 2006 is able to simulate pre-seasonal pollen concentrations in Denmark, where key components include a well calibrated emission model and emission inventory. Furthermore, all model components are prepared for full implementation in the THOR air pollution and forecasting system. 
During pre-seasonal, pollen allergy patients are in general medically unprotected. Such episodes will therefore have a full impact with respect to allergic reactions among the allergy patients. The use of the integrated approach improves knowledge of such episodes. Furthermore, an implementation of DEHM-Pollen in the THOR system has the potential to provide early warnings of severe pre-seasonal pollen episodes to the entire Danish population, by forecasting how far and how severe a possible pre-seasonal birch pollen cloud will progress into Denmark. 